\title{
Designing an Artifact to Support Incentives for Medication Adherence
}

\author{
Alan Yang \\ University of Nevada, Reno \\ alany@unr.edu
}

\author{
Mala Kaul \\ University of Nevada, Reno \\ $\underline{\text { mkaul@unr.edu }}$
}

\author{
Upkar Varshney \\ Georgia State University \\ uvarshney@gsu.edu
}

\begin{abstract}
This research is motivated by the current trend towards utilization of mobile technology in healthcare interventions. Despite academic and practitioner efforts, lack of medication adherence continues to be a leading indicator of poor health outcomes and increased hospitalizations worldwide. There are several incentive systems that remain relatively unexplored in the field of medication adherence. Our analysis of the current academic research and medication adherence applications indicates a research gap and an opportunity to create a significant contribution through the design of an application (app) addressing the complex problem of medication adherence. Therefore, we propose the design of an app to positively influence patient behavior through incentives to improve medication adherence. The contribution of this research is a novel design utilizing multiple incentive types to improve patient adherence and wellbeing.
\end{abstract}

\section{Introduction}

The lack of medication adherence (MA) leads to high costs of healthcare worldwide, in terms of both health outcomes and increased hospitalization of patients [1, 2]. The goal of bringing medication adherence to a satisfactory level, such as $80 \%$ for most chronic conditions and $95 \%$ for HIV/AIDS, has been a major challenge for medical practitioners [3, 4]. The difficulty in achieving this goal for the patient arises from multiple factors, including forgetfulness, cognitive decline, fear of addiction, fear of side effects, lack of dose efficacy, and loss of motivation to follow a medication regimen [5]. Several interventions have been proposed in the literature to improve MA with limited success. These interventions generally focus on reminders, family support, patient education, visits by healthcare professionals, and smart systems for monitoring of MA [6].

The current state of application design for medication adherence focuses on educational interventions and reminder systems [7]. One of the developments in this field is the use of technology supported mechanisms to incentivize MA $[8,9]$. Our analysis of the existing academic literature and medication adherence apps indicates that there is rich literature on the use of mobile apps for healthcare selfmanagement [10]. There is also substantial literature on the use of gamification in app design for healthcare apps [11]. There is an independent set of literature on the use of gamification for behavior modification [12]. Prior research has also indicated that significant positive relationships exist between of social connectivity, social support and medication adherence; This phenomenon includes connectivity with social groups, providers (such as doctors, clinicians, nurses), and other supporting individuals such as family members and health coaches. [13-15]. Social connectivity is prevalent in certain types of healthcare apps such fitness tracking [16] and chronic disease management [17].

However, social connectivity is not prevalent in the MA literature and the research space is relatively unexplored. There is also limited use of gamification features in app design in the design of MA apps. Finally, several existing MA apps are lacking in usability and connectivity to a healthcare provider. This feature is more important in the area of MA because unlike fitness or nutrition, MA-related lapses can have more immediately critical negative outcomes. Despite the enormous interest in MA apps, we find a research gap in the area of medication adherence apps to positively influence patient behavioral change [7], specifically through the use of gamification, social connectivity and links to providers/support groups [18]. This motivates us to create a valuable contribution through the researchbased design of an app using gamification and connectivity to social groups and providers, as a solution to the complex practical problem of MA.

Adherence is a behavior, to affect this behavior, the specific question that this research focuses on, is as follows: How to design a mobile app to improve medication adherence using gamification and connectivity to social/support groups and providers? To address this question, we consider what are the factors that are important for a design to improve MA. Since our research question regards the specific aspect 
of designing a mobile app for behavior incentivization in a healthcare context, we examine extant literature pertaining to the design of incentives for MA. gamification, tracking and (social) connectivity. We also demonstrate the ways in which our research will extend/improve upon what already is known about designing incentives for MA.

Based on our review of the extant literature described in Section 2, we identify the design requirements for addressing the problem of incentivizing MA. Design Science Research (DSR) is a well-established information systems research paradigm appropriate for the construction of sociotechnical artifacts for practical, "real-world" change interventions [27, 28]. Section 3 describes the method and Section 4 presents our initial design for the MA application. Designing is an evolutionary and iterative process [29]; Section 5 describes the proposed build and evaluate process for the app [30].

\section{Theoretical Background}

We examined MA, incentives for positive health behaviors, and mobile application functionalities to begin answering the question of what design would improve medication adherence rates. In our search, we focused on 3 relevant literature streams: motivation, medication adherence, and data sharing. The motivation literature discusses various forms of incentives [31, 32] for behavior modification [33, 34]. This led to an additional focus on incentives and interventions in our review. Mobile applications are a well-established mechanism in healthcare settings [35], especially for reminders [36]. Apps also have unique capabilities that make them very appropriate for our study. They lend themselves well for gamification [37], tracking, and support data sharing and social connectivity [38, 39].

Timely intake of medicine is an important part of treatment for many health conditions. Failure to adhere to medication schedules can lead to adverse health effects and incur costs to healthcare providers in the form of emergency room visits and more frequent inpatient care [40]. In severe cases, failure to take medicine can lead to death, while taking too much medication within a non-scheduled interval of time can cause an overdose or chemical addiction [41, 42]. Medication adherence is a field of study focused on increasing the amount timely and appropriate administration of medication for patients [43]. We summarize the terminology and the scope of its use in our research (Table 1).
Table 1 Summary of terms used in this research

\begin{tabular}{|c|c|}
\hline Term & Description and Scope \\
\hline Intervention & $\begin{array}{l}\text { An action taken to improve the } \\
\text { health, physical or mental, of an } \\
\text { individual }[19,20] \text {. We focus on } \\
\text { medical interventions. }\end{array}$ \\
\hline Incentive & $\begin{array}{l}\text { A motivation offered to an } \\
\text { individual with the intent to } \\
\text { promote a specific behavior [21]. } \\
\text { We focus on incentives meant to } \\
\text { induce behaviors beneficial to } \\
\text { health. }\end{array}$ \\
\hline Gamification & $\begin{array}{l}\text { The process of enhancing services } \\
\text { with motivational affordances } \\
\text { resembling game-related systems } \\
\text { to achieve behavioral outcomes } \\
{[22,23] \text {. We focus on }} \\
\text { gamification as a form of } \\
\text { incentive to both provide positive } \\
\text { feedback and prolong positive } \\
\text { health behavior (adherence). }\end{array}$ \\
\hline Data Sharing & $\begin{array}{l}\text { The spread of information } \\
\text { through a network that can be } \\
\text { uniquely traced back to an } \\
\text { individual [24-26]. We focus on } \\
\text { data sharing between patient and } \\
\text { healthcare provider in a } \\
\text { healthcare context. }\end{array}$ \\
\hline $\begin{array}{l}\text { Mobile } \\
\text { Health }\end{array}$ & $\begin{array}{l}\text { A system enabled through } \\
\text { wireless infrastructure that } \\
\text { provides healthcare to individuals } \\
\text { in a manner that decreases } \\
\text { spatial and temporal constraints } \\
{[19,20] \text {. We focus on mobile }} \\
\text { health as it applies to patient- } \\
\text { facing smartphone applications. }\end{array}$ \\
\hline
\end{tabular}

\subsection{Interventions for Health Behavior}

We define medical interventions as "activities directed at an individual with the goal of improving health" [9]. Medical interventions can take on many forms. In the field of MA, interventions are designed to incentivize patients into following medication schedules. These interventions can range from the simple, such as reminder systems, to complex, such as networked applications that incorporate patient data and the actions of healthcare providers [7]. We focus on incentive-based interventions while acknowledging the existence of other intervention types. The selected focus on incentives is a deliberate choice to specify the scope of this research, we do not intend to argue that one form of intervention is superior to another. 


\subsection{Financial Incentives}

One form of incentives for behavior modification is financial incentives [44]. Definitions for financial incentives include any motivational tool that has a monetary impact on individuals. Distinctions made between types of financial incentives in academic studies include the form of the incentive (Cash, vouchers, lottery, and cost reduction), the type of illness being treated (chronic or acute, physical or mental), and the economic status of the patient [45].

Studies involving financial incentives typically target individuals with incomes slightly below or at the national average. Some methods of incentives such as cost-sharing were more effective when applied to lowincome patients [46]. Cash incentives have been used as part of studies focused on patients with both mental and physical disorders to improve adherence rates [47, 48]. The duration of most studies is 6 to 12 months and few studies track how well patients maintain adherence after the intervention was over [49].

\subsection{Gamification}

The commonly referenced definition of gamification is "the use of game design in non-game contexts", described in [50-52]. This definition has since expanded, with works describing what constitutes game design, what is considered a nongame context and frameworks expanding the scope of gamification to include user, system design, and outcomes [53]. We define gamification as the process of building a system with design principles associated with game development. 'System' we define as any environment where users interact with technology for the purpose of completing a task.

There are different interpretations of what comprises a gamified system. Common categorizations of gamified system elements describe the distinction between gamification elements and gamification processes. There are multiple ways these categorizations have been described, including objects and mechanics, motivational affordance, and game conditions [54]. Gamification elements are concepts and sensory experiences commonly associated with gamified designs. These include items such as badges, achievements, progress bars, and rewards [44] . These elements are meant to present information in a way that is more likely to retain user attention and serve as a mechanism to reinforce behaviors leading up to their presentation to the user [52]. Further, the object of gamification is not necessarily to incorporate gameplay or to make the activity "fun"; Rather, it is to use game design techniques and/or game elements for solving real-world problems [51, 52].

\subsection{Data sharing}

A unique feature of mobile technologies is the ability to constantly transmit data provided a network connection exists. While data transmission is not a new phenomenon, the ubiquity of mobile networks allows for near constant transmission of data pertaining to phone use, location, and more [55]. Data sharing has also transformed many industries, as the sheer number of data streams allows for rapid adaptation of products, services, and advertising [56].

In the field of healthcare, the increase in data sharing allows for closer monitoring of patient conditions and rapid response to any healthcare issues that may arise [57, 58]. Healthcare provider monitoring of MA benefits greatly from data sharing as well. The communication bottleneck of a tech-less provider-patient relationship is the frequency with which a patient visits a physician and the quality of the communication between the two parties. These visits can be spread between weeks and months. Recorded adherence to medication is determined by a combination of physical benchmarks and patient disclosure [59, 60]. Data sharing allows for daily reporting of health status, shifting the communication bottleneck to the healthcare provider and the amount of time they can spend reviewing patient-provided data [61]. Application of basic heuristics and data analysis can also generate an environment where health alerts are automated and the need for constant human monitoring is only required in emergency situations [62]. These innovations, properly implemented, give providers more accurate and timely information pertaining to a patient's health.

\subsection{Existing Incentive Designs}

We conducted a review of the twenty-two most popular MA applications on the Apple store. 18 out of the 22 apps were also available in the android store. The search process used the term "Medication Adherence" and chose only apps that specifically stated adherence improvement as one of their features. Applications focused on fitness or dieting were filtered at this stage. Informed by the literature review, we reviewed the apps for usability and specifically examined them for the capabilities in the following categories: progress tracking, gamification, reward mechanism, social capability, and connection to a physician.

Progress tracking is the extent to which an application provides the ability to track past 
performance and provides feedback to the user on their degree of adherence. Given the considerations of security and privacy of health-related personal information, [63, 64], our proposed design incorporates settings to enable the user to customize their information sharing preferences. This would enable the app user to use progress tracking for their personal goal management. Gamification was the existence of one or more gamified elements in the application. Examples include badges, achievement tracking, and leaderboards. Reward mechanisms are some form of positive reinforcement provided to app users for maintaining adherence levels. Examples include vouchers, coupons, and in-app tokens redeemable for cash. Social capability is some form of connectivity either to other users on an application or a social networking site. In-app examples include message boards and wikis. External social networking examples include a prompt for a user to make a tweet, post to Facebook, or share to Instagram after an event has occurred. Connection to a physician is an application feature that links the user to a healthcare provider. This link can be in the form of direct contact such as an email address, or information on relevant insurance options, hospitals, or physicians.

Table 2 in Appendix A summarizes our review of the features and capabilities of current MA apps. Our review shows that there is no app that includes the design features discussed above. Although most apps provide daily tracking, we found that none of the apps use any form of gamification or virtual reward mechanisms, which are crucial to incentivizing behaviors. The surveyed apps provided limited social capabilities and limited physician connectivity.

\section{Method}

Since our research objective is to design a practical solution for a particularly complex problem that can significantly impact healthcare outcomes, we adopt a Design Science Research based theoretically, supported approach for our study. DSR is a wellestablished paradigm in conducting "improvement research", i.e. research that has a dual mandate of combining the utilizing knowledge (and theory) for problem-solving through the creation of novel or innovative artifacts... [29]. DSR seeks to provide relevant solutions to complex practical problems [28, $30,65,66]$. It is especially suited to providing evidence-based design solutions to problems that are practical in nature, including both managerial and social problems [67] at the intersection of technology and society $[67,68]$.

We lean on well-established DSR approaches for design science research. We align our work with the process put forward by Hevner's three cycle approach that accommodates design to be both rigorous and relevant [30]. We merge this with Peffers et al's staged Information Systems Design Science Research methodology [65]. The overall approach is summarized below in Figure 1.

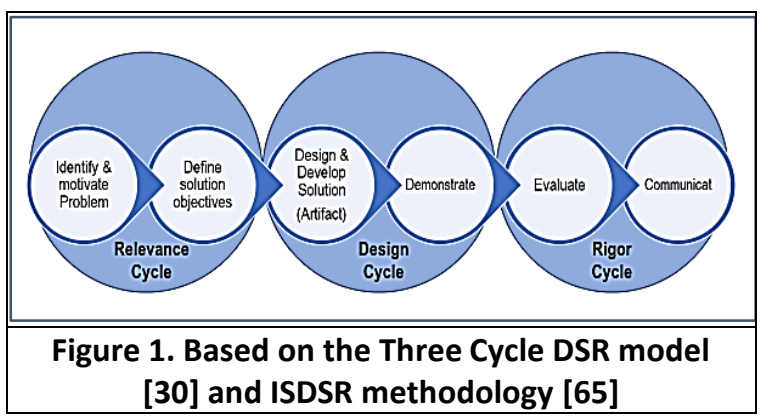

The relevance cycle motivates the practical problem of MA which defines the research problem including the definition of requirements for the design of a technological solution to improve MA. The design cycle uses design knowledge from the extensive methodological and theoretical bases of design, human behavior and technological impacts to adopt a rigorous, scientific approach and use the theoretical lenses of gamification to design an incentive-based model for addressing the practical problem of MA. We develop our design based on research into evidencebased MA interventions using mobile apps; the use of incentives to affect behavior change [69], gamification principles [11], the role of gamification in affecting behavior change [70], and social connectivity [71, 72]. We also draw on human computer interaction design knowledge [73, 74] so the app is usable for a wide range of users. The build and evaluate steps are informed by the Design and Rigor steps in Figure 1; they will be applied in the evaluation and development proposed in Section 5 below.

\subsection{Initial Design}

Based on the above analysis, we identify the gap in literature and MA apps and define the initial problem requirements space as well as our scope and assumptions. The main goal of the app is to improve patient health. For the MA app to be successful:

a. it must incentivize or motivate the patient

b. to achieve its primary goal, the application needs to convey timely and accurate information

c. The application should be easy to understand and use by all stakeholders (patient, provider, support group) 
d. The application should generate utility to the user beyond immediate healthcare benefits to increase the chances of continued usage

e. it must be able to incentivize or motivate the patient on an ongoing basis (or the duration of the medication) - this will demonstrate adherence

An assumption we make is that the main users of the app will be patients, with connected health-care providers such as nurses and doctors viewing the outputs of the application. By prioritizing the setting and the stakeholders of the design space, we establish that the following features as being most important to the design of a MA app: progress tracking, gamification, reward mechanism, social capability, and connection to a physician.

\section{Design of the Prototype}

The application design and the connections between screens are summarized in Figure 6 in the Appendix. Below we discuss the details of our design.

\subsection{Opening Screen (Figure 2)}

When the user opens the app, they are presented with the title of the app and four options. The design is informed by usability principles with a focus on simplicity of information and clarity of options. The opening screen links to the four main navigation options of schedule, recording, files, and reward. These options are persistent across the screens as options and allow the user to quickly navigate the application. In the two screens where the four navigations options are not available due to space, the recording screen and the medication screen, the back button will navigate the user to either the main menu or the schedule screen, both of which have the four options available.

\subsection{Schedule Screen (Figure 3)}

The schedule screen presents a calendar to the user so that they can view their medication schedule, schedule new medications, and update their schedule. The design decisions that informed the design of this screen were clarity of information and ease of use. By presenting medications in the form of a calendar, users can quickly see what medications they need to take each day of the week for the month. The current screen has a locked monthly view. This design is to present consistency of information, so users are not presented with conflicting messages as they schedule and view their medications. If a user wishes to schedule for a future month, they can navigate between months in the tab above the calendar. Users can also establish new medication schedules by clicking on the days they are required to take the medication. Days that the user has medications scheduled will be tinted a different color, so users can tell immediately whether they will need to take medication that day. Selection of a date will lead the user to the medication screen, where they can add a new medication or modify an existing one. Future functionality would allow for healthcare providers to access and update the patient's schedule.

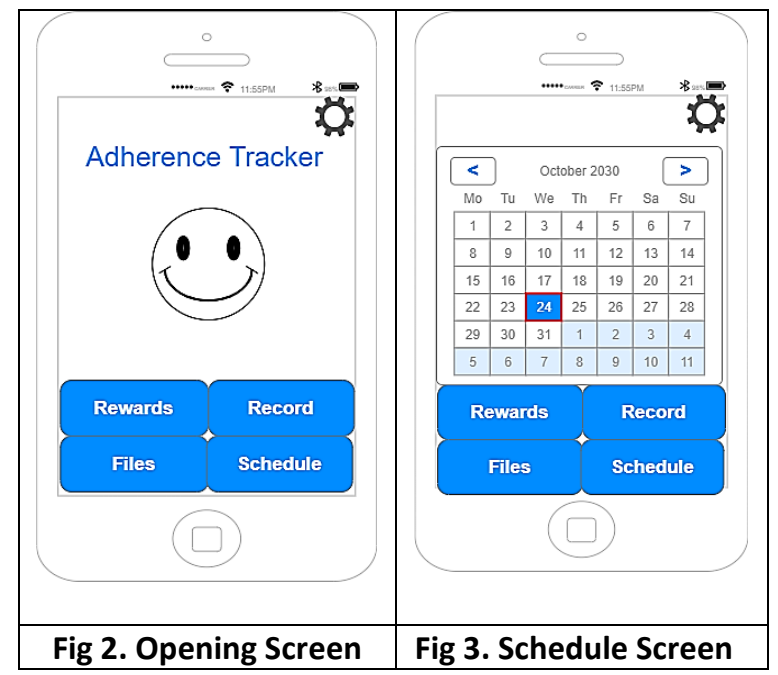

\subsection{Medication Screen (Figure 4)}

The medication screen allows users to schedule medications that they are taking. To streamline information delivery, users are presented with a nonscrolling screen with two main points of focus: their medication, and whether it is recurring. Currently the options for recurring doses are daily, weekly, or monthly as these are the most common medication schedules for prescription and non-prescription medicines. Future functionality will include more customization to accommodate unique schedules, e.g. users can indicate that they want to take medication every 3 days or on Tuesdays every other week.

\subsection{Recording Screen (Figure 6 S2)}

The recording screen provides the user the option to record themselves taking their medication with their cellphone's camera. Upon navigation to the screen, the user will be prompted to allow the application access to their camera to take videos and photos. Users also have the option to take a photo if they do not wish to make a recording or if their phone is not capable of recording video. Once the recording is made, the application will ask for storage permissions on the phone to create files. The videos and photos can then be stored on the user's phone and can be quickly 
accessed through the "files" tab on the application for either personal review or to share with a healthcare provider to verify adherence to a medication schedule.

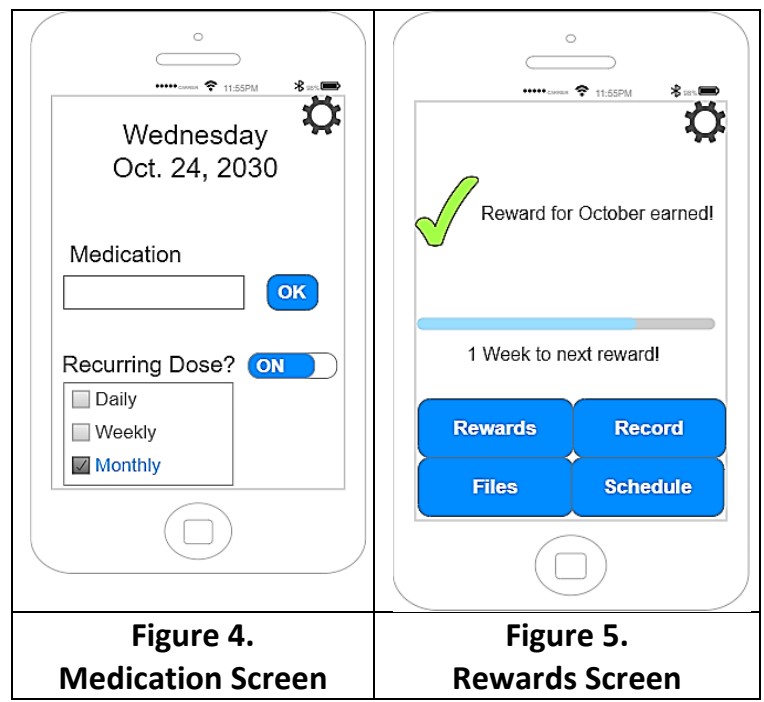

\subsection{Rewards Screen (Figure 5)}

This screen provides users a view of their rewards for MA and is the central focus of the application. There is a monthly progress bar that continually fills and an indicator for whether the current month's award has been earned. Every Sunday of each week, the user's adherence is checked. If the user was adherent to their medication for that week, the progress bar is incremented by 1 week. If the user failed to adhere to their medication that week, the progress bar does not progress. Notifications will occur during this check to recapture the user's attention to motivate continued usage of the system and serve as another form of incentive. The monthly progress bar is reset each month and at the end of the month, if the user had at least three weeks of adherence, they will earn a reward. The progress bar and monthly completion can be linked to future gamification designs and incentives. An example scenario of the gamification feature of achievements would have a user completing a month of completion being rewarded the 'bronze' badge. Completion of 3 months would reward the user with the 'silver' badge. Completing a year would reward the user the 'gold' badge. Implementation of rewards can also incorporate multiple incentive types. Social incentives can be implemented as the option to share progress and achievements through social sites such as Facebook or Instagram and can positively reinforce prolonged periods of adherence. Financial incentives could take the form of monthly rewards for meeting adherence goals. These incentives can include vouchers for local stores, gift cards for online retailers, digital currency, and direct cash deposits.

The design can also be adapted for different patients and medications. Healthcare providers can adjust adherence duration, adherence reward threshold, and the number of allowed adherence failures based on the patient, their health conditions, and the medication(s) they are taking. Hospitals could engage in cost sharing with patients as an incentive to decrease the cost of each hospital visit. Similar costsharing benefits have been successfully applied in multiple industries, including airline, restaurant, and more $[75,76]$.

\subsection{Files Screen (Figure 6 S5)}

The files screen allows users to access any videos or photos they have taken with the application. It would access the common 'gallery' application present on most smartphones and would serve as a way for users can review their previous adherence rates. With patient consent, healthcare providers could also look at this screen to determine whether patients were adherent and for how long. External verification of these files, either by a healthcare provider or another $3^{\text {rd }}$ party, would confirm the user's adherence and trigger gamified events, such as badges and achievements, and make them eligible for rewards.

\subsection{Settings Screen (Figure 6 S7)}

In the settings, users can decide on the functions they want to enable. If all the application functions are disabled, the app would serve as a basic scheduling system for keeping track of medication. Users have the option to disable progress tracking, rewards, and provider sharing. Users can also add contact information for their healthcare providers. Future app functionality could allow for quick messaging of saved videos, with timestamps, to the email addresses of healthcare providers for verification of adherence without the need for a physical visit to a clinic.

\section{Proposed Evaluation and Conclusion}

The proposed design will initially be evaluated by stakeholders representing two different groups $-\mathrm{i}$. patients, ii. providers using web-based surveys [77]. Based on the feedback on this evaluation we will begin app design and develop a prototype artifact as a proof of concept [27]. We propose to evaluate this artifact to assess its usability and applicability using both artificial (researcher tested) as well as naturalistic (user-tested) approaches [78]. Since the nature of the problem is critical to the health outcomes, we propose 
to also evaluate the artifact summatively in a naturalistic environment by including a local medical group [79-81]. We plan to use the data that accrues from these evaluations to reiterate and improve upon the app design and effectiveness of our proposed solution $[65,82]$ to ultimately derive significant, generalizable nomothetic design knowledge [29] in the form of a formalized set of design principles and more detailed design rules [67]. MA remains a pressing issue that affects many people around the world. We seek to address this problem by examining the obstacles in the MA setting and creating a solution for it. Further development of this work can lead to a new solution to better address the problem of MA through behavioral incentives in a planned, usercentric way. We present this work with the goal of motivating development of medication adherence incentives for different patient groups.

\section{References}

[1] E. L. McQuaid and W. Landier, "Cultural issues in medication adherence: disparities and directions," Journal of general internal medicine, vol. 33, pp. 200206, 2018.

[2] G. Loewenstein, D. A. Asch, and K. G. Volpp, "Behavioral economics holds potential to deliver better results for patients, insurers, and employers," Health Affairs, vol. 32, pp. 1244-1250, 2013.

[3] S. M. Sweeney and P. A. Vanable, "The association of HIV-related stigma to HIV medication adherence: a systematic review and synthesis of the literature," AIDS and Behavior, vol. 20, pp. 29-50, 2016.

[4] B. Vrijens, S. Antoniou, M. Burnier, A. de la Sierra, and M. Volpe, "Current situation of medication adherence in hypertension," Frontiers in pharmacology, vol. 8, p. 100, 2017.

[5] U. Varshney, "Smart medication management system and multiple interventions for medication adherence," Decision Support Systems, vol. 55, pp. 538-551, 2013.

[6] V. S. Conn, T. M. Ruppar, K. C. Chan, J. DunbarJacob, G. A. Pepper, and S. De Geest, "Packaging interventions to increase medication adherence: systematic review and meta-analysis," Current medical research and opinion, vol. 31, pp. 145-160, 2015.

[7] L. Dayer, S. Heldenbrand, P. Anderson, P. O. Gubbins, and B. C. Martin, "Smartphone medication adherence apps: potential benefits to patients and providers," Journal of the American Pharmacists Association, vol. 53, pp. 172-181, 2013.

[8] S. M. Badawy and L. M. Kuhns, "Economic evaluation of text-messaging and smartphone-based interventions to improve medication adherence in adolescents with chronic health conditions: a systematic review," JMIR mHealth and uHealth, vol. 4, p. e121, 2016.

[9] R. Q. Wolever, L. A. Simmons, G. A. Sforzo, D. Dill, M. Kaye, E. M. Bechard, et al., "A systematic review of the literature on health and wellness coaching: defining a key behavioral intervention in healthcare,"
Global advances in health and medicine, vol. 2, pp. 3857, 2013.

[10] M. Dadgar and K. D. Joshi, "The role of information and communication technology in self-management of chronic diseases: An empirical investigation through value sensitive design," Journal of the Association for Information Systems, vol. 19, p. 2, 2018.

[11] A. S. Miller, J. A. Cafazzo, and E. Seto, "A game plan: Gamification design principles in mHealth applications for chronic disease management," Health informatics journal, vol. 22, pp. 184-193, 2016.

[12] E. A. Edwards, J. Lumsden, C. Rivas, L. Steed, L. Edwards, A. Thiyagarajan, et al., "Gamification for health promotion: systematic review of behaviour change techniques in smartphone apps," BMJ open, vol. 6, 2016.

[13] D. Scheurer, N. Choudhry, K. A. Swanton, O. Matlin, and W. Shrank, "Association between different types of social support and medication adherence," The American journal of managed care, vol. 18, pp. e4617, 2012.

[14] M. Vyavaharkar, L. Moneyham, A. Tavakoli, K. D. Phillips, C. Murdaugh, K. Jackson, et al., "Social support, coping, and medication adherence among HIV-positive women with depression living in rural areas of the southeastern United States," AIDS patient care and STDs, vol. 21, pp. 667-680, 2007.

[15] M. Hennessey and J. W. Heryer, "When information is insufficient: Inspiring patients for medication adherence and the role of social support networking," American health \& drug benefits, vol. 4, p. 10, 2011.

[16] P. Simões, A. G. Silva, J. Amaral, A. Queirós, N. P. Rocha, and M. Rodrigues, "Features, behavioral change techniques, and quality of the most popular mobile apps to measure physical activity: systematic search in app stores," JMIR mHealth and uHealth, vol. 6, p. e11281, 2018.

[17] M. Dadgar and K. Joshi, "ICT-Enabled SelfManagement of Chronic Diseases: Literature Review and Analysis Using Value-Sensitive Design," in 2015 48th Hawaii International Conference on System Sciences, 2015, pp. 3217-3226.

[18] I. Ahmed, N. S. Ahmad, S. Ali, S. Ali, A. George, H. S. Danish, et al., "Medication adherence apps: review and content analysis," JMIR mHealth and uHealth, vol. 6, p. e62, 2018.

[19] U. Varshney, "Pervasive healthcare and wireless health monitoring," Mobile Networks and Applications, vol. 12, pp. 113-127, 2007.

[20] U. Varshney, "Mobile health: Four emerging themes of research," Decision Support Systems, vol. 66, pp. 2035, 2014.

[21] R. Town, R. Kane, P. Johnson, and M. Butler, "Economic incentives and physicians' delivery of preventive care: a systematic review," American journal of preventive medicine, vol. 28, pp. 234-240, 2005.

[22] J. Hamari, J. Koivisto, and H. Sarsa, "Does gamification work?--a literature review of empirical studies on gamification," in 2014 47th Hawaii 
international conference on system sciences, 2014, pp. 3025-3034.

[23] K. Huotari and J. Hamari, "Defining gamification: a service marketing perspective," in Proceeding of the 16th international academic MindTrek conference, 2012, pp. 17-22.

[24] E. A. Bell, L. Ohno-Machado, and M. A. Grando, "Sharing my health data: a survey of data sharing preferences of healthy individuals," in AMIA Annual Symposium Proceedings, 2014, p. 1699.

[25] M. M. Mello, V. Lieou, and S. N. Goodman, "Clinical trial participants' views of the risks and benefits of data sharing," New England Journal of Medicine, vol. 378, pp. 2202-2211, 2018.

[26] G. Nanibaa'A, N. A. Sathe, A. H. M. Antommaria, I. A. Holm, S. C. Sanderson, M. E. Smith, et al., "A systematic literature review of individuals' perspectives on broad consent and data sharing in the United States," Genetics in Medicine, vol. 18, pp. 663671, 2016.

[27] S. Gregor and A. R. Hevner, "Positioning and presenting design science research for maximum impact," MIS quarterly, pp. 337-355, 2013.

[28] A. R. Hevner, S. T. March, J. Park, and S. Ram, "Design science in information systems research," MIS quarterly, pp. 75-105, 2004.

[29] R. L. Baskerville, M. Kaul, and V. C. Storey, "Genres of inquiry in design-science research: Justification and evaluation of knowledge production," Mis Quarterly, vol. 39, pp. 541-564, 2015.

[30] A. R. Hevner, "A three cycle view of design science research," Scandinavian journal of information systems, vol. 19, p. 4, 2007.

[31] D. M. Kreps, "Intrinsic motivation and extrinsic incentives," The American economic review, vol. 87, pp. 359-364, 1997.

[32] P. Milne, "Motivation, incentives and organisational culture," Journal of knowledge management, 2007.

[33] M. N. K. Boulos, S. Wheeler, C. Tavares, and R. Jones, "How smartphones are changing the face of mobile and participatory healthcare: an overview, with example from eCAALYX," Biomedical engineering online, vol. 10, p. 24, 2011.

[34] D. West, "How mobile devices are transforming healthcare," Issues in technology innovation, vol. 18, pp. 1-11, 2012.

[35] K. A. Kannisto, M. H. Koivunen, and M. A. Välimäki, "Use of mobile phone text message reminders in health care services: a narrative literature review," Journal of medical Internet research, vol. 16, p. e222, 2014.

[36] L. Sardi, A. Idri, and J. L. Fernández-Alemán, "A systematic review of gamification in e-Health," Journal of biomedical informatics, vol. 71, pp. 31-48, 2017.

[37] H. M. Abu-Dalbouh, "A questionnaire approach based on the technology acceptance model for mobile tracking on patient progress applications," J. Comput. Sci., vol. 9, pp. 763-770, 2013.

[38] S. Asimakopoulos, G. Asimakopoulos, and F. Spillers, "Motivation and user engagement in fitness tracking: Heuristics for mobile healthcare wearables," in Informatics, 2017, p. 5.
[39] A. S. M. Mosa, I. Yoo, and L. Sheets, "A systematic review of healthcare applications for smartphones," BMC medical informatics and decision making, vol. 12, p. 67, 2012.

[40] M. C. Sokol, K. A. McGuigan, R. R. Verbrugge, and R. S. Epstein, "Impact of medication adherence on hospitalization risk and healthcare cost," Medical care, pp. 521-530, 2005.

[41] R. Balkrishnan, "Predictors of medication adherence in the elderly," Clinical therapeutics, vol. 20, pp. 764-771, 1998.

[42] M. E. Gatti, K. L. Jacobson, J. A. Gazmararian, B. Schmotzer, and S. Kripalani, "Relationships between beliefs about medications and adherence," American Journal of Health-System Pharmacy, vol. 66, pp. 657664, 2009.

[43] W. Y. Lam and P. Fresco, "Medication Adherence Measures: An Overview," BioMed research international, vol. 2015, pp. 1-12, 2015.

[44] D. Easley and A. Ghosh, "Incentives, gamification, and game theory: an economic approach to badge design," ACM Transactions on Economics and Computation (TEAC), vol. 4, pp. 1-26, 2016.

[45] A. Yang and U. Varshney, "A taxonomy for mobile health implementation and evaluation," 2016.

[46] A. Tarasiuk, G. Reznor, S. Greenberg-Dotan, and H. Reuveni, "Financial incentive increases CPAP acceptance in patients from low socioeconomic background," PLoS One, vol. 7, 2012.

[47] D. Claassen, "Financial incentives for antipsychotic depot medication: ethical issues," Journal of medical ethics, vol. 33, pp. 189-193, 2007.

[48] A. B. Staring, C. Mulder, and S. Priebe, "Financial incentives to improve adherence to medication in five patients with schizophrenia in the Netherlands," Psychopharmacol Bull, 2010.

[49] A. Burton, S. Marougka, and S. Priebe, "Do financial incentives increase treatment adherence in people with severe mental illness? A systematic review," Epidemiology and Psychiatric Sciences, vol. 19, pp. 233-242, 2010.

[50] S. Deterding, D. Dixon, R. Khaled, and L. Nacke, "From game design elements to gamefulness: defining" gamification"," in Proceedings of the 15th international academic MindTrek conference: Envisioning future media environments, 2011, pp. 9-15.

[51] S. Deterding, "Gamification: designing for motivation," interactions, vol. 19, pp. 14-17, 2012.

[52] R. N. Landers, E. M. Auer, A. B. Collmus, and M. B. Armstrong, "Gamification science, its history and future: Definitions and a research agenda," Simulation \& Gaming, vol. 49, pp. 315-337, 2018.

[53] D. Liu, R. Santhanam, and J. Webster, "Toward Meaningful Engagement: A Framework for Design and Research of Gamified Information Systems," MIS quarterly, vol. 41, 2017.

[54] J. Koivisto and J. Hamari, "The rise of motivational information systems: A review of gamification research," International Journal of Information Management, vol. 45, pp. 191-210, 2019. 
[55] S. Ilarri, E. Mena, and A. Illarramendi, "Locationdependent query processing: Where we are and where we are heading," ACM computing surveys (CSUR), vol. 42, pp. 1-73, 2010.

[56] R. Belk, "You are what you can access: Sharing and collaborative consumption online," Journal of business research, vol. 67, pp. 1595-1600, 2014.

[57] A. J. Adler, N. Martin, J. Mariani, C. D. Tajer, O. O. Owolabi, C. Free, et al., "Mobile phone text messaging to improve medication adherence in secondary prevention of cardiovascular disease," Cochrane database of systematic reviews, 2017.

[58] J. Thakkar, R. Kurup, T.-L. Laba, K. Santo, A. Thiagalingam, A. Rodgers, et al., "Mobile telephone text messaging for medication adherence in chronic disease: a meta-analysis," JAMA internal medicine, vol. 176, pp. 340-349, 2016.

[59] M. R. DiMatteo, K. B. Haskard-Zolnierek, and L. R. Martin, "Improving patient adherence: a three-factor model to guide practice," Health Psychology Review, vol. 6, pp. 74-91, 2012.

[60] L. N. Ngoh, "Health literacy: a barrier to pharmacistpatient communication and medication adherence," Journal of the American Pharmacists Association, vol. 49, pp. e132-e149, 2009.

[61] Y.-L. Zheng, X.-R. Ding, C. C. Y. Poon, B. P. L. Lo, H. Zhang, X.-L. Zhou, et al., "Unobtrusive sensing and wearable devices for health informatics," IEEE Transactions on Biomedical Engineering, vol. 61, pp. 1538-1554, 2014.

[62] K. Santo, S. S. Richtering, J. Chalmers, A. Thiagalingam, C. K. Chow, and J. Redfern, "Mobile phone apps to improve medication adherence: a systematic stepwise process to identify high-quality apps," JMIR mHealth and uHealth, vol. 4, p. e132, 2016.

[63] T. Glenn and S. Monteith, "Privacy in the digital world: medical and health data outside of HIPAA protections," Current psychiatry reports, vol. 16, p. 494, 2014.

[64] B. C. Zapata, A. H. Ninirola, J. L. Fernandez-Aleman, and A. Toval, "Assessing the privacy policies in mobile personal health records," in 2014 36th Annual International Conference of the IEEE Engineering in Medicine and Biology Society, 2014, pp. 4956-4959.

[65] K. Peffers, T. Tuunanen, M. A. Rothenberger, and S. Chatterjee, "A design science research methodology for information systems research," Journal of management information systems, vol. 24, pp. 45-77, 2007.

[66] S. T. March and G. F. Smith, "Design and natural science research on information technology," Decision support systems, vol. 15, pp. 251-266, 1995.

[67] J. E. Van Aken and G. Romme, "Reinventing the future: adding design science to the repertoire of organization and management studies," Organization Management Journal, vol. 6, pp. 5-12, 2009.

[68] S. A. Carlsson, "Towards an information systems design research framework: A critical realist perspective," in Proceedings of the First International Conference on Design Science Research in Information Systems and Technology, Claremont, CA, 2006, pp. 192-212.
[69] B. J. Fogg, "Persuasive technology: using computers to change what we think and do," Ubiquity, vol. 2002, p. 2, 2002.

[70] B. Cugelman, "Gamification: what it is and why it matters to digital health behavior change developers," JMIR serious games, vol. 1, p. e3, 2013.

[71] M. R. DiMatteo, "Social support and patient adherence to medical treatment: a meta-analysis," Health psychology, vol. 23, p. 207, 2004.

[72] J. A. Kulik and H. I. Mahler, "Social support and recovery from surgery," Health Psychology, vol. 8, p. 221, 1989.

[73] A. Sonderegger, S. Schmutz, and J. Sauer, "The influence of age in usability testing," Applied Ergonomics, vol. 52, pp. 291-300, 2016.

[74] P. Zaphiris, M. Ghiawadwala, and S. Mughal, "Agecentered research-based web design guidelines," in CHI'05 extended abstracts on Human factors in computing systems, 2005, pp. 1897-1900.

[75] D. Jang and A. S. Mattila, "An examination of restaurant loyalty programs: what kinds of rewards do customers prefer?," International Journal of Contemporary Hospitality Management, 2005.

[76] M. Lederman, "Do enhancements to loyalty programs affect demand? The impact of international frequent flyer partnerships on domestic airline demand," The RAND Journal of Economics, vol. 38, pp. 1134-1158, 2007.

[77] T. K. Schleyer and J. L. Forrest, "Methods for the design and administration of web-based surveys," Journal of the American Medical Informatics Association, vol. 7, pp. 416-425, 2000.

[78] J. Venable, J. Pries-Heje, and R. Baskerville, "FEDS: a framework for evaluation in design science research," European journal of information systems, vol. 25, pp. 77-89, 2016.

[79] C. Sonnenberg and J. Vom Brocke, "Evaluations in the science of the artificial-reconsidering the buildevaluate pattern in design science research," in International Conference on Design Science Research in Information Systems, 2012, pp. 381-397.

[80] Y. Sun and P. B. Kantor, "Cross-Evaluation: A new model for information system evaluation," Journal of the American Society for Information Science and Technology, vol. 57, pp. 614-628, 2006.

[81] J. Venable, J. Pries-Heje, and R. Baskerville, "A comprehensive framework for evaluation in design science research," in International Conference on Design Science Research in Information Systems, 2012, pp. 423-438.

[82] K. Peffers, M. Rothenberger, T. Tuunanen, and R. Vaezi, "Design science research evaluation," in International Conference on Design Science Research in Information Systems, 2012, pp. 398-410. 


\section{Appendix}

Table 2. Comparison of 22 Medication Adherence Applications

\begin{tabular}{|c|c|c|c|c|c|c|}
\hline App Name & Progress Tracking & Gamification & Reward mechanism & Social capabilities & Connecting to physician & Availabile on Android \\
\hline Dosecast & Last pill & No & No & No & Yes & Yes \\
\hline Pill Reminder & Daily & No & No & No & No & Yes \\
\hline iPatient Care & Daily & No & No & No & No & No \\
\hline Carezone & Monthly & Yes & No & In-app discussion & Yes & Yes \\
\hline Memo Health Pill & Daily & No & No & No & No & Yes \\
\hline Propeller Health & Daily & No & No & No & No & Yes \\
\hline ScalaMed & Daily & No & No & No & Yes & Yes \\
\hline Every Dose, Every Day & Daily & No & No & No & Yes & Yes \\
\hline DoseSmart & Daily & No & No & No & No & Yes \\
\hline HealthAssist & Daily & No & No & In-app discussion & No & Yes \\
\hline Plan-it Med & Daily & No & No & No & No & Yes \\
\hline My uBox & Daily & No & No & No & No & No \\
\hline AcuDose & Daily & No & No & No & No & No \\
\hline MedManage Daily Medicaiton Log & Lifetime & No & No & No & No & Yes \\
\hline Symptom Tracker \& Health Diary & Daily & No & No & No & No & Yes \\
\hline CeyHello & Daily & No & No & No & No & No \\
\hline Hero: Medication manager & Bi Weekly & No & No & No & No & Yes \\
\hline Rxremind Medicaiton Reminder & Daily & No & No & No & Yes & Yes \\
\hline EllieGrid & Weekly & No & No & No & No & Yes \\
\hline Hailie & Daily & No & No & No & No & Yes \\
\hline Smart Med Reminder & Daily & No & No & No & No & Yes \\
\hline MediMan & Daily & No & No & No & No & Yes \\
\hline
\end{tabular}

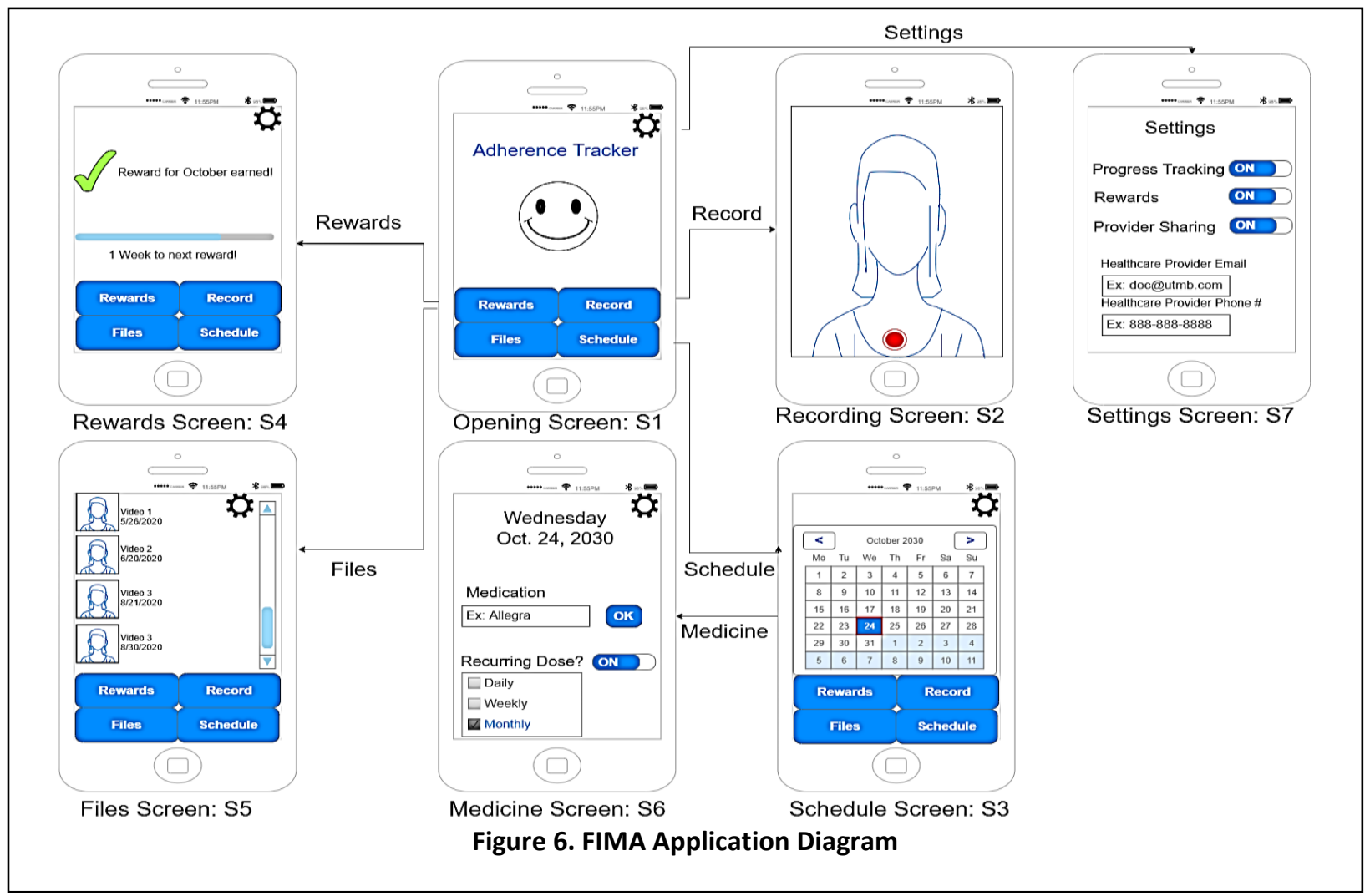

